\title{
Impact of Mass Media in Creating Political Concern in Bangladesh
}

\section{Mortuza Ahmmed, International University of Business, Agriculture and Technology, Bangladesh}

\begin{abstract}
This Paper develops a framework of political socialization in Bangladesh. This study is exploratory and explanatory in nature and investigates political socialization through media. Media is a lifeline of socialization. This study describes the terms political socialization and political communication. The field of political communication interacts between media and political systems at local, national and international level. Public opinion is made in democracy by voting and responding to polls besides participating in elections. Special emphasis has been put on electioneering campaigns, voting behaviors and role of media in creating political awareness. Influences on political content of the mass media have been studied through triangulation method; qualitative and quantitative approaches are combined for valid inferences. From media content one may infer many of the facts or influences that shaped it. This paper investigates assorted influences on political discourses disseminated through Bangladeshi mass media.
\end{abstract}

Keywords: Mass Media, Political Communication, Public Opinion, Voting Behaviors. 


\section{Introduction}

Today, every one of us is spending more of our leisure time watching TV, listening to the radio or reading newspapers and magazines. The shows on the TV and the articles in the newspapers influence our decision process, shaping our perceptions for the world. Besides the positive fact that we are better informed and in touch with the latest news, we should be aware that accepting this enormous flow of information and allowing it to make our mind can be dangerous. The TVs infiltrate our lives, guiding us what are we supposed to wear, how we are supposed to look and act.Media content is an indicator of many other underlying forces. Contents of media provide a glimpse of the people and organization that produce them and help to understand and explore phenomenon that are less open and less visible. Content is not a product prepared and produced in isolation rather it is the outcome of many a factors including consumers' demands, organizational factors, extra organizational factors, and social processes that contribute to its production. Media exist in certain community and cannot cut off its relation with the society. Mass media always had been an important means of communication. Over a period of time it has passed through various changes and has gradually acquired a new significance and importance in the present times. Earlier it used to be small in size and in the strict control of the authoritarian governments to "Control Public Mind". The primary purpose of media is to ensure a well informed citizenry for our social and political structure. The mass media provides information and programs that can promote democracy. Communication system's democratization has not gained much attention in the individual countries despite of political awareness in masses. Media can ensure smooth functioning of a democratic system which is linked with media role for diffusion in field of innovations and information. The basic aim of democracy in Bangladesh is to work for a democratic system representing opinion of the public. The development of democratic Government by the people is determined through interaction of democracy with public's aspirations regarding formation of Government in accordance with their desires. The political stakeholders like politicians, political parties etc play pivotal role in representative democracy through maintaining link between people and those having political powers. In this way, establishment of political power structure and various interests of citizens are balanced. Formation of public opinion and mobilization are caused due to involvement of media, political institutions and other networks. 
The process of socialization can be defined as creating a sense of interaction with world by gaining and adopting norms, values and traditions of other cultures. Adoption of other cultures is over-dominating our own culture in a process of socialization. Since our childhood, we acquire knowledge about how to behave in a socially acceptable manner. Some social segments have very powerful impact in socialization of young generations like family and (schools), whereas other institutions have also strong effect on process of socialization though not intentional. Now we are looking for the place of media in socialization. It has been observed that an average American high school student remain in front of TV for more time than in a class. Mass Media is considered as strong agent of socialization. The role of television in Bangladesh is extremelyimportant as illiteracy is a major obstacle toinformation and awareness. An increasingnumber of women, urban and rural, now have access totelevision. Due to the limited scope of the print media tothe audio-visual media becomes the most influentialagent in the country.

\section{Literature Review}

There are many factors that determine what will be transmitted and how it will be treated. Political economy of the media approach facilitates to explore media contents from a different perspective (Murdock \& Golding, 1997). Not everything 'eligible' to be mass media content actually gets into the media. Some critics suggest that journalists consciously bias their news reports in line with their personal attitudes (Gieber, 1964). With respect to the news production, one striking feature is the great reliance of journalists on a limited, official and otherwise legitimized source through a network of contacts and procedures. The heavy reliance on such sources by the media people is justified as 'sources of facts' and to substantiate other 'facts'.Most research on effects from political communication has concentrated on the individual rather than society at large; in other words micro-level effect studies are over shadowed while macro level studies dominate the literature.

Tumber and Prentoulis (2003) suggest that we may be witnessing a paradigmatic shift in journalism: from detachment to involvement, from verification to assertion, from objectivity to subjectivity. There is a fundamental contradiction between the natures of peace process and news values, the media often play a destructive role in attempts at making peace (Wolfsfeld, 2004). Those who run the media tend to favor four values: immediacy, drama, simplicity and ethnocentrism. These values make it difficult to use the media for peace.Hart (1991) referred 
to fragmentary presentation as resulting in "cameo politics". Dramatization occurs whenever news is selected on the basis of its dramatic or entertaining value rather than its importance as an issue. Normalization takes place whenever news stories show how particular problems can be solved within the existing political system.

Roper (1975) as quoted by Mark (1982) in his research concluded that people usually got most of the news about what is going on in the world from T.V when Roper's organization asked a national cross-section about this in 1974, 65 percent replied T.V and only 47 percent said newspapers. Gans (1980), Gitlin (2003) and Shoemaker and Reese (1991) have suggested five broad hypotheses to address varied influences on production end. From media content one may infer many of the influences that shaped it. The research proves that journalists' worldviews,their perceptions of social reality may influence their work (Shoemaker \& Reese, 1991). News as a product, consciously or unconsciously carries influences exerted at various levels.

Chaffee \& Berger (1997) found that news stories are more influenced by reporters' personal opinions as compared to the editors and readers. Peterson et.al found that papers business editors were more favorably disposed towards capitalism than were the general public. It can be concluded that the attitudes, views and beliefs of a communicator affect upon content and if the communicators have more power over their messages and less constraints, their personal attitudes, values and beliefs more often influence content. Communicator's professional role and ethical framework can also influence content.Bennett (2001) identified four news flaws common in news coverage: personalization, fragmentation, dramatization, and normalization. Personalization means individuals are more focused in news stories when reporting on large scale social concerns. Fragmentation is the outcome of competition and increased commercialization that focuses much on the delivery of news in disconnected, brief capsule summaries.

\section{Articulation of Political Discourse}

Research in the field of mass communication has been focusing the process and effects of massmedia contents. The researchers concentrated on micro-level or individual level analysis. Accordingto Shoemaker (1991) mass communication research can be categorized into the following two dimensions: 


\section{Micro Level Influences}

Personal characteristics, professional background, personal attitudes and professional roleconception of media workers are micro level influences that affect upon media content. Thesefactors construct peculiar attitudes, values and beliefs that are mixed up with professionalbackgrounds and experience. Personal traits sometimes result in biased approach in peculiarcircumstances. A journalist observes and constructs reality according to his perception. Theselection of world to describe the same event or camera angle and shot to depict the same happeningwill be different if more than one journalist is employed to that assignment. It is so because personalcharacteristics vary from person to person.It is assumed that attitudes, beliefs and values of a journalist influence upon his construction ofreality. Personal political attitudes and religious orientations also effect upon media content. Forexample, a journalist whose political views match to a party will treat news of that party in adifferent way as compared to journalist whose political views and attitudes do not match with it.Employment patterns, traditional stereotypes and socialization patterns affect each individual in a different way but these factors also harmonize thinking style and approach. Under developingcountries most often relate expertness to demography as we consult foreign correspondents to coversome complicate and complex phenomenon. Women are not considered as talented as menespecially in our society. This stereotype thinking affects the approach of common man.

The nature of job and the status of a journalist affect his content. New employees learn many thingsfrom their seniors. Professional role, policy and coworkers who create an atmosphere of sharedvalues in an organization determine ethics. Media workers are obliged to follow the code of ethicsthat influences upon the selection and treatment of the content. Though there is no direct influenceof communicator's characteristics, backgrounds and experiences on media content but these factorsindirectly influence upon content because of their intrinsic nature. Professional roles determine thecriterion of selection and construction of reality. Economic survival and economic considerations,political views and instances along with other factors shape ideology. In Marxist societies, theruling elite own mass media so media emerge as a tool to show power. Events are interpreted fromthe perspective of powerful interests. 


\section{Macro Level Influences}

Ideology and extra media influences fall in this category. Extra media factors produce greatinfluence on media content. Media as an agent of social control identify the threat to the status quo by deviants (Boyd-Barrett, 1977). Patterns of content show that powerful get news coverageroutinely to control mechanism in society. Ideology is not an individual belief system rather it is asocietal level phenomenon. Ideology denotes to total structure that governs the perceptions ofindividuals about themselves and the outer world.The model described by Shoemaker and Reese (1991) has five levels represented by five concentricrings. The innermost ring represents the individual decision-maker; the second ring is the mediaroutines level; third is the organization level; fourth is the extra media level; and fifth is theideological level. At each of these levels, there are influences that presumably have an impact on thedecisions that lead to news content.It is not possible for any media organization to cover all the events happening around the world byitself. It has to depend upon sources that are of various types working at multiple levels likeindividuals, organizations, interest groups, public relations practitioners, government, and so on.Sources that provide news to media organizations sometimes withhold information or lie. Thereexist overt and covert ways to influence media content. Information embedded in a particularcontext and construction of reality in specific and favorable perspective cannot be easily identified(McChesney, 2000). Through information subsidies media organizations get easier and cheaperusable information (Herman \& McChesney, 1997). Journalists are sometimes engaged and keptbusy in ways that they could not find time to approach alternative views.

Newspapers editor accept and reject potential news stories for highly subjective reasons, which canbe based on the editor's own experiences, attitudes, and expectations. All these elements are relatedto the ideology of that individual. Journalists sometimes follow their personal agenda that influenceson the content. The selection or rejection of stories is determined by the ideology the mediamaintains. Potential stories are based on agreed-upon values. Selection of information sources is the discretionary power of media organizations but powerfulinformation sources exert pressure to get their side of the story. Journalists prefer organizationalsources to individual ones because it is easier for journalist to use information from organizationalsources than from individual because of accessibility and credibility. Organizationalsources are easily available whereas individuals do not have sufficient time and resources tocompete effectively for the journalists' attention that's why official sources are 
more preferredbecause of availability and credibility. Media organizations get news from other competingorganizations, electronic media monitoring, print media and wire services and so on. Each source treatsevents in its own style and constructs reality in its ideological paradigm.Public relations departments issue materials to media organizations that assist them to control costs.Through information subsidies media content are influenced. These information sources influencethe content by constructing realities in special contexts and perspectives. Pseudo-events are stagedto get public attention that ultimately results in media coverage.Technological revolution has rubbed the boundaries of mass media and started producing content for widerange audiences. Technological advancement provided multiple channels and choices to audiences.Newspapers that use computer composing have fewer mistakes than others. Satellite technology is beingused to transmit national editions of newspapers at global level. With the emergence of global mediatransnational communities have emerged that facilitated the growth of global advertising campaigns.

\section{Methodology}

This study is based on triangulation method. Qualitative and quantitative methods are applied. Political contents of Bangladeshi media are analyzed and its impact on literate youth is measured through survey. This integrated study to measure effects of political content may help to evaluateand judge the extent to which mass media are performing their roles in Bangladeshi society. Data forthe analyses and valid inferences are collected through survey and interviews. Survey methodhelped to get details from practicing reporters, sub-editors, editors, producers, and anchors. The dataassisted to explore the micro and macro level influences on the articulation of political discourse inthe media.Survey from media and nonmedia students helped to compare and evaluate viewership patterns, likings, awareness and the influence of political discourses. Since youth is the most importantsegment of population for the progress and development of a society, it seems necessary to evaluate the impact of political content on the youth. Interviews facilitated to make valid inferences about thearticulation of political discourses in the media.Six types of influences on political contents of the media are observed through survey:

\section{Political Influence}

Government controls privately owned media in different ways. Controls are entertained through laws, regulations, licenses and taxes. Government owned media are controlled 
through media financing. Politicians, government officials and civil servants make all editorial and programming decisions. Censorship policies are executed to control the content. Interest groups want to communicate their viewpoints to the public and try to influence legislation as well as public opinion and behaviors. Interest groups sometimes provide guidelines to cover topics of their interest and establish lobbies to influence mass media. Interest groups apply critical approach to influence media policy, content and workers as to get maximum coverage. They threat media by planning boycotts, protests and influencing sponsors and advertisers. Interest groups sometimes use public relations campaigns to get public attention and coverage. They successfully get in media agenda through their campaigns by designing and holding events that the mass media will cover.

\section{Economic Influence}

Mass media try to compete others to get maximum number of audience and advertisers. Characteristics of the market place in which a medium operates can influence its content. Market driven media try to satisfy the needs of greater audience and this struggle sets peculiar trends and patterns. Institutionalized media and media conglomeration are the results of such trends. Competition is assumed to create a marketplace of ideas that facilitate free discussions and expression on important issues. Some media corporations are interlocked with financial institutions. Boards of directors from non-media institutions serve as journalists and prove a threat to the autonomy of mass media. Reality is constructed in the perspective of advertiser and unfavorable information is withheld. Multinational manufacturers and advertisers have considerable power to suppress and kill unwanted political messages.

\section{Organizational Influence}

Intra organizational influences on media content are various like the kind of roles an organizationplays, its goals, internal structure, technology, market, ownership and policy. Organizationalroutines are followed by top-down approach, higher authorities issue policies that are implementedat lower levels. All members of a media organization are answerable to their owners and topmanagement. Norms and values of media organizations define structure, role specialization,standards, interchangeability of personnel, and commonly held conceptions of what the contentshould be. Potential stories are based on agreed-upon values of the organization.All media organizations have to assign roles and develop structures in order to smoothly run mediaorganization. Media organization's assigned roles are of three levels; the 
front line that consists ofreporters and creative staff; the middle level consists of managers, editors and producers whocoordinate between top level and bottom level routines; the top level consists of news executivesand corporate who make policies and set budgets. Assigned roles shape the opinions and determineviews of the people working in an organization.

\section{Procedural Influence}

Marshall McLuhan (1964) contends that medium is the message means that media are not just channels of information, media carry many other things along with the message that construct the reality for a receiver. One cannot completely understand the effects of any version of social reality if one does not understand the forces that shape it. Media routines are the patterned and repeated practices implied by media workers. Media workers develop routines that become standardized and institutionalized owing to their utility. Routines help an organization to avert constraints and pressures. For example, people demand maximum information and it is not possible for a media organization to cover all the events happening around the world so they are obliged to contact with news agencies, establish bureaus and beat of reporters. Reporters face time constraint because they have to submit news stories before the deadline. This constraint effects the shaping of news substance. Media routines inculcate an approach in a journalist to consider an event as news or not. It can be inferred that an organization's routines lead a journalist to define an event as news.

\section{Social/Reference Group Influence}

Bangladesh is a heterogeneous society where every group, race, casts and creed wants its domination on media organization. They want to introduce and cultivate their specific culture, values, norms and ideology. Every group attempts to influence media to get maximum and positive coverage that affects on media content. News and entertainment contents are cultural manifestations that are why the reality represented through it is culturally constructed. Power relations can help us to understand the culture and the patterns of media portrayal because each person does not possess equal power, so, power relations get more representation and in turn indicate who is powerful and who is powerless in the existing culture. Overrepresentations and repeated representations convey the message of importance while under representation or misrepresentation gives the message of lack of power. News revolves around the concept of 'power' so news sources are around the powerful people even media relying upon officials, wealthy people, and corporate and bureaucratic elite for news. Media 
content at the same time emerge as a manifestation of culture as well as source of culture (Galtung and Vincent, 1992). The community also influences mass media where they work. Social, political, economic and cultural traits of that community affect the kind of media working there and produce continuous influence on its content. Larger communities exert more influence while larger media organizations have more power to sustain that influence.

\section{Professional Influence}

Journalism and social science share similar claims, routines, objectives and restrictions. Claims ofboth fields are accuracy, objectivity and truthful representation of the world but both facerestrictions. In order to fulfill their claims, journalists follow accepted professional routines andpractices to attain reliability and credibility. The acknowledgement of credibility and reliabilityguides journalists to take given information as highly reliable rather to see them as filtered one andthus put a check to explore various factors involved in 'communicator category.' According toTuchman (1978), objectivity is a ritual that serves primarily to defend the organizational productsfrom critics. The objectivity helps journalists to satisfy maximum numbers of audience. Selectedcontent is placed on a paper in a way to absorb audience attention and interest. Television messagesare designed to appeal large audience. Presentation techniques and formats are developed thatultimately appear as media routines.News contents inform us about changing scenarios and alert us to things that are now going well soit is impossible to consider proportionate representation in news. Intra organizational influences onmedia content are various like the kind of roles an organization plays, its goals, internal structure,technology, market, ownership and policy. Media organizations now consist of large sections thathave acquired their own routines so it is not possible for an individual to have direct contact withthem all. Organizational routines are followed by top-down approach; higher authorities issuepolicies that are implemented at lower levels. All members of a media organization are answerableto their owners and top management. Usually organizations are profit oriented so their first prioritybecomes economic gains but they do not totally ignore professional objectives. This situation givesrise to peculiar media routines in which economic considerations serve as constraints. 
Table 1: One - Sample Statistics

\begin{tabular}{|l|c|c|c|c|}
\hline & $\begin{array}{c}\text { Sample } \\
\text { size }\end{array}$ & Mean & $\begin{array}{c}\text { Standard } \\
\text { Deviation }\end{array}$ & $\begin{array}{c}\text { Standard Error } \\
\text { Mean }\end{array}$ \\
\hline Political influence & 24 & 8.4850 & 2.14203 & 0.37921 \\
\hline Economical influence & 24 & 3.8310 & 1.08666 & 0.20213 \\
\hline Organizational influence & 24 & 10.3421 & 3.14027 & 0.59416 \\
\hline Procedural influence & 24 & 3.9517 & 1.07461 & 0.20193 \\
\hline Professional influence & 24 & 12.9184 & 2.97521 & 0.68924 \\
\hline
\end{tabular}

\section{Findings}

a) It is assumed that media workers who have a journalism degree produce content with different characteristics than do those with other majors. It is believed that journalists with proper education and degree perform differently but in Bangladesh the situation is not mush clear, as the trend of employing professional degree holders is not set in. Staff in our prints and electronic media is not usually equipped with the professional education of their filed and media routines are extensively followed.

b) Individual media workers' backgrounds, experiences and social relations affect the coverage of media contents. Journalists are more likely attuned to select news from their social circles that result in the ignorance of other fields' news. Treatment of news is also different among the experienced, educated and stringers. Similarities affect the type, coverage and treatment of news. Similarities of cast, creed, language, community and inter personal ties effect the coverage of news content.

c) Media produce reality that is socially constructed. The construction of reality is effected by media workers' personal attitudes if organizations do not follow strong routines. Reporters can manipulate facts while covering events and issues. Associations with a certain political party, pro government attitude, religious party affiliations, perceptions and other factors that produce a particular behavior and attitude, affect on the media content. Journalists' role conceptions affect content.

d) Social pressures work as driving force and journalists do their duties according to the perceived ethics. Though ethics are not in black and white form but journalists usually avoid those activities that are considered unethical. Ethics can vary from country to country and community to community. Private channels in Bangladesh are telecasting political talk shows that carry unethical humor, remarks, and satire. However ethics of 
print media workers vary because of market forces, personal attitudes and mediated meanings of ethics.

e) Media routines strongly effect on media workers' perceptions and develop peculiar attitudes among them that cause to produce content attuned to media policies. Routines build up an occupational paradigm and media workers get accustomed of it with the passage of time. One can recognize the writings of a columnist that has been working for a certain newspaper. Routines guide media men what to do and what not to do, what is sanctioned by their media organization and what is not welcomed. This understanding is the result of long interaction and association with a particular media organization.

f) Media organizations do not disseminate all the content received by them. In gate keeping, contents that are closely related to organizational routines are more likely to be entertained. BTV follows particular routines and the content contrary to the routines is less like to be selected. For example, news of deviants is less prominently covered and if some journalists cover it in a positive and dominant way, it will lose the chance of selection. The more media workers learn the routines associated with their jobs, the more professional they are rated by coworkers. Professionalism is associated with following the routines of media organization. All the media organizations do not follow the same routines so the definition of professionalism differs from organization to organization. Coworkers compel a journalist to follow the routines so as to get professional.

g) On stories or subjects without established routines, in early stages of an issue, for example, individual factors will be relatively more influential compared with routines. The content is more likely to be influenced by media workers' attitudes if a media organization has not established routines for that story or subject. Routines cultivate specific attitudes that help to handle an issue, story or event and escape the content for individual's personal influence.

h) The closer an event is to the media organization's routine definition of newsworthiness; the more likely it is to be covered. The major criteria of media organizations for information selection are newsworthiness and news peg but the definition of newsworthiness is not the same for all media. Media organizations want to develop consistency in their coverage over time so coverage is guided by the routine practices. The more journalists cover an event, the more similar their coverage 
will be. The more that journalist read each other's stories, the more similar is their subsequent coverage of an event or issue. Journalists follow the same patterns and practices in the coverage of events so similarities in covering news do occur. Moreover, editors test the credibility and truth worthiness of event by comparing it with other journalist's coverage. Journalists confirm the validity of their viewpoints by matching them with the other. This trend sets similarities for the treatment of events and issues by journalists.

i) Bangladeshi media organizations' personnel can be classified in upper-level, middlelevel and lower-level. Upper-level staff determines the policy and takes decision, middle level staff gives first priority to media goals and lower level staff concentrates more on information sources. When editorial routines conflict with the organization's need to make a profit, if the editor control both the business and editorial sides of a newspaper, the editorial side will be given a lower priority than the business side. Media organizations are generally profit oriented so in case of any conflicting views between ideology and business, the later is preferred. Media construct social realities so they are more closely connected with social institutions. The higher an individual is in a media organization, the more likely he or she is to have connections with nonmedia organizations. Non-media organizations approach and develop relations with media men to get coverage and projection. That's why high officials of a media organization are linked with close social networks especially with power elite.

j) 12. The more a media organization promotes itself within a target audience, the more its content will reflect the interests of that audience. Organizations set their agenda according to the likings of their audience. Not only audience but advertisers also influence media content.

\section{Conclusion}

The results of this study give support to the "Mobilization" approach, suggesting that the more people use mass media for political information, the more they tend to participate in different forms of political actions. Giving credit to the second-level agenda-setting theory to explain cognitive effects of mass media in a transitional society, this study provides evidence that citizens learn from the media about the efficacy and integrity of political institutions in their country, thus gaining an in-depth understanding of their general performance. Consequently, the information acquired through news media becomes an important dimension of attitude 
formation towards those political institutions. This study provides theoretical argumentation and empirical evidence suggesting that by affecting different levels of political trust, mass media create an environment in which citizens are not blindly submissive and trusting but neither totally distrustful of the political institutions in their country. This, in turn, leads to a more participatory citizenry who feel that their influence on political authorities is necessary but also possible. Yet, media effects in transitional societies are not overreaching. Similar to the evidence from Western countries, they are rather contingent on the media platform where news is consumed (print vs. broadcasting vs. online), the source of information (independent vs. partisan-oriented media), and on the audience characteristics (need for orientation and political ideology). The evidence from this study suggests that rather than inducing opinion change, media effect in a transitional society are more likely to crystallize previous predispositions. Particularly, the existence of a pluralistic partisan press in some transitional societies might provide to have a rather important role in building partisan loyalties and stabilizing the volatile electorate, characteristic for transitional societies. 


\section{References}

Boyd-Barrett, J. O. (1977). Media imperialism: Towards an international framework for an analysis of media systems. In J. Curran, M. Gurevitch and J. Woollacott (Eds.), Mass communication andsociety. London: Edward Arnold Hodder Headline Group. p. 116135 .

Boyd-Barrett, J.O. and Thussu, D.K. (1993). NWICO strategies and media imperialism: The case of regional news exchange. In K. Nordenstreng and H. Schiller (Eds.), Beyond national sovereignty:International communication in the 1990s. Norwood, NJ: Ablex Publishing Corporation. pp. 177-192.

Chaffee, M. \& Berger, W. (1997). Setting the community agenda, In Journalism \& Mass Communication Quarterly, 73 (1), (pp. 7-16).

Ericson, R. V., Baranek, P. M. \& Chan, J. B. L. (1987). Visualizing deviance: a study of news organization. Toronto: University of Toronto Press.

Freedom House. (1997). Freedom in the world: The annual survey of political rights and civil liberties. 1996-1997. Washington, DC: Freedom House.

Gans, H. (1980). Deciding what's news: A study of CBS Evening News, NBC Nightly News, Newsweek, and Time. New York: Vintage Books.

Gitlin, T. (2003). The whole world is watching: Mass media in making and unmaking of the new left. Berkley: University of California Press.

Hart, A. (1991). Understanding the media: A practical guide. New York: Routledge Herman, E. S. \& McChesney, R. W. (1997). The global media, the new missionaries of capitalism, London: Cassell.

Robinson, M. J. \& Sheehan, M. A. (1980). Over the wire and on TV: CBS and UPI in Campaign 80. New York: Sage Publications.

Shoemaker, Pamela J. \& Stephen D. Reese. (1991). Mediating the Message: Theories of influences on mass media content, New York: Longman.

Tumber, H. \& Prentoulis, M. (2003) Journalists under fire: subcultures, objectivity and emotional literacy. In D. K. Thussu and K. Thussu (Eds.)., War and the media: reporting conflict 24/7. London: Sage Publications

Wolfsfeld, G. (2004). Media and the path to peace. New York: Cambridge University Press. 